\title{
Temperature gradients in the rabbit eye
}

\author{
A. R. YESLIN AND P. S. SHURRAGER \\ ILLINOIS INSTITUTE OF TECHNOLOGY
}

Temperature measurements of the eyes of adult albino rabbits showed consistent gradients from the anterior surface of the retina to the outer surface of the cornea. Average difference between temperature at the retina and at the outer surface of the cornea was $5.01{ }^{\circ} \mathrm{C}$. Between rectal temperature and temperature at the outer surface of the cornea, average difference was $5.84^{\circ} \mathrm{C}$. Temperalure readings at points on the surfaces of ocular structures showed a consistent tendency to be highest in the lower nasal quadrant and lowest in the upper distal quadrant.

Duke Elder (1940) attributed circulation of intraocular fluid to three influences: primary metabolic interchange, pressure circulation, and thermal circulation (a purely physical phenomenon) within the anterior chamber caused by difference in temperature between the air-cooled cornea and the vascularized iris. He refers to his own research in 1927 in which a difference of $3^{\circ} \mathrm{C}$ to $5^{\circ} \mathrm{C}$ was found between the cornea and the iris of rabbit eyes, and to the research with rabbits of v. Michel in 1886 and Nelson in 1927.v. Michel reported rectal temperature as $38.5^{\circ} \mathrm{C}$, temperature in the middle of the anterior chamber as $31.9^{\circ} \mathrm{C}$, and in the lens as $36.1^{\circ} \mathrm{C}$. Nelson found average differences of $1.5^{\circ} \mathrm{C}$ and $3.5^{\circ} \mathrm{C}$ between rectal temperature and temperature of the aqueous humor of the closed and open eye respectively. In the present study, a series of temperature readings was made from the anterior surface of the retina to the outer surface of the cornea in order to establish a more comprehensive map of temperature gradients in the eye.

\section{Method}

Seven adult albino rabbits, anesthetized with either phenobarbitol or eurathane, were used. Temperature measurements were made with Veco thermistors, types $55 \mathrm{~A} 1,52 \mathrm{Al}$, and $47 \mathrm{~A} 1$, with a GR bridge to measure resistance changes. Calibration points of the thermistors were established with an ice bath $\left(0^{\circ} \mathrm{C}\right)$ and the melting point of Benzophenone $\left(48.5^{\circ} \mathrm{C}\right)$.

Eyelids were permanently reflected and the eye penetrated in the top distal quadrant by a hypodermic needle (outside diameter, .05 in) containing a thermistor. The needle was then withdrawn and temperature measurements made at selected loci. In three animals, both eyes were used, consecutively. In the other four animals, measurements were taken in only one eye, two being left and two right eyes.

Temperature readings were taken at the anterior surface of the retina, in the vitreous body, and at the posterior surface of the lens, posterior surface of the iris, and posterior and anterior surfaces of the cornea. In the vitreous, thermistors were located in the center of the eye approximately half way between the anterior surface of the retina and posterior surface of the lens.

At the beginning and end of each series of temperature measurements from an eye, rectal temperatures were recorded. The mean of these two readings was taken as rectal temperature for a given animal.

\section{Resulis and Discussion}

Figure 1 shows average temperatures of 10 rabbit eyes at various loci in the vertical and horizontal planes of the eye. Temperature rises consistently from the outer surface of the cornea to the anterior surface of the retina. When average readings at five points on ret-
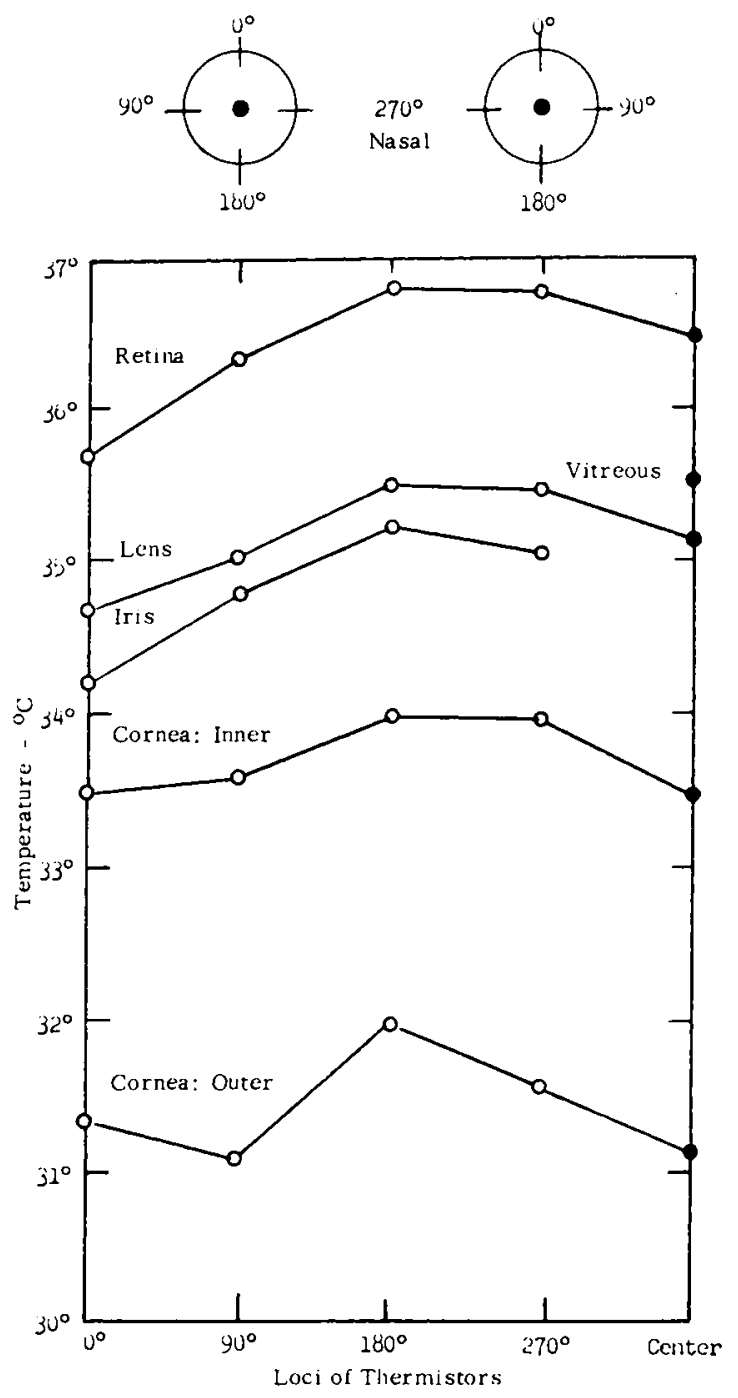

Fig. 1. Mean temperatures of 10 rabbit eyes at various loci. 
ina, lens and inner and outer surfaces of the cornea were averaged, they yielded values of $36.39^{\circ} \mathrm{C}, 35.13^{\circ} \mathrm{C}$, $33.67^{\circ} \mathrm{C}$, and $31.38^{\circ} \mathrm{C}$ for these structures respectively. The average of temperatures at four points on the iris was $34.81^{\circ} \mathrm{C}$, and the average temperature in the vitreous body was $35.46^{\circ} \mathrm{C}$.

All measures were relatively consistent from eye to eye. The largest standard deviation was $0.73^{\circ} \mathrm{C}$ for readings at a single locus in the vitreous body. Other standard deviations were $0.39^{\circ} \mathrm{C}$ for readings at the retina (5 loci) and iris (4 loci), and $0.30^{\circ} \mathrm{C}, 0.21^{\circ} \mathrm{C}$, and $0.11^{\circ} \mathrm{C}$ respectively for readings at the lens and inner and outer surfaces of the cornea (5 loci each).

Within the vertical planes there is a slight but consistent tendency for temperatures to be highest in the lower nasal quadrant and lowest in the upper distal quadrant. The average of readings taken at locus $180^{\circ}$ was $34.67^{\circ} \mathrm{C}$; at locus $270^{\circ}, 34.54^{\circ} \mathrm{C}$; at locus $90^{\circ}$, $34.14^{\circ} \mathrm{C}$; and at locus $0^{\circ}, 33.85^{\circ} \mathrm{C}$.

Average rectal temperature was $37.22^{\circ} \mathrm{C}$, with a standard deviation of $0.72^{\circ} \mathrm{C}$.

The significance of the data is that they show consistent gradients in temperature in both the anterior and posterior chambers of the eye and at points in vertical planes within these chambers. They are not necessarily representative of normal temperatures in the rabbit eye because (1) animals were anesthetized, (2) eyelids were reflected, thereby exposing atypical cooling surfaces, and (3) the effects of pressure and loss of fluid caused by penetration of the eye are unknown.

\section{Reference}

Duke Elder. Sir w. S. Textbook of opthalmology: I. The develupment, form, and function of visual apparatus. St. Louis, Mo.: C. V. Mosby Co., 1940. 